Research Paper:

\title{
Evaluation of Pre-Hospital Emergency Services, Non- Surgical Interventions, and Clinical Outcomes in Patients With Traumatic Spine
}

Sasan Andalib ${ }^{1,2,3}$, Zahra Mohtasham-Amiri ${ }^{1}$, Shahrokh Yousefzadeh-Chabok ${ }^{1,2,3^{*}}$, Alia Saberi ${ }^{2}$, Maryam Kakovan ${ }^{1}$, Leila KouchakinejadEramsadati $^{1} \mathbf{Q}$, Sara Sayad-Fathi ${ }^{2} \mathrm{Q}$, Hadiseh Shokatjaliil ${ }^{1} \mathrm{Q}$, Samaneh Ghorbani-Shirkouhi ${ }^{2} \mathrm{Q}$

1. Guilan Road Trauma Research Center, Poursina Hospital, School of Medicine, Guilan University of Medical Sciences, Rasht, Iran

2. Neuroscience Research Center, Poursina Hospital, School of Medicine, Guilan University of Medical Sciences, Rasht, Iran

3. Department of Neurosurgery, Poursina Hospital, School of Medicine, Guilan University of Medical Sciences, Rasht, Iran

\begin{tabular}{c|l}
$\begin{array}{c}\text { Use your device to scan } \\
\text { and read the article online }\end{array}$ & $\begin{array}{l}\text { Cittation: Andalib S, Mohtasham-Amiri Z, Yousefzadeh-Chabok Sh, Saberi A, Kakovan M, Kouchakinejad-Eramsadati L, et al. } \\
\text { Evaluation of Pre-hospital Emergency Services, Non-Surgical Interventions, and Clinical Outcomes in Patients With Traumatic } \\
\text { Spine. Iran J Neurosurg. 2019; 5(1):31-36. http://dx.doi.org/10.32598/irjns.5.1.31 }\end{array}$ \\
d def:: http://dx.doi.org/10.32598/irjns.5.1.31
\end{tabular}

(c) $0(3$

Article info:

Received: 24 Jun 2018

Accepted: 10 Oct 2018

Available Online: 01 Jan 2019

Keywords:

Spine trauma, Spinal cord injury, Glasgow Comma Scale, Emergency medical services

\section{ABSTRACT}

Background and Aim: The aim of this study was to assess the pre-hospital emergency services, non-surgical interventions, and clinical outcomes in patients with traumatic spine referred to Poursina hospital in Guilan.

Methods and Materials/Patients: Spine trauma registry of Poursina hospital of Rasht were used. Records of patients with traumatic spine were reviewed for pre-hospital emergency services, nonsurgical interventions, and clinical outcomes during 2015 to 2019.

Results: 197 patients with traumatic spine were reviewed. $80.2 \%$ of the patients were transferred by ambulance. Pre-hospital fixation was performed in $59.4 \%$ of the patients $(n=117)$. Pre-hospital intubation was required in $1 \%$ of patients $(n=2) .4 .6 \%$ of the patients had Glasgow Comma Scale (GCS) $<9 ; 3 \%$ of them $(n=6)$ had $9<\mathrm{GCS}<12$; and $92.4 \%$ had $\mathrm{GCS} \geq 13.11 .7 \%$ of the patients experienced $\mathrm{SCl} .6 .1 \%, 1 \%, 3 \%, 0.5 \%$, and $1 \%$ of the patients suffered from paraplegia, paraparesis, quadriplegia, quadriparesis, hemiparesis, respectively. Surgery was performed in $89.8 \%$ of the patients. Traction was performed for $3.6 \%$ of the patients. Good recovery, moderate disabilities, severe disabilities, persistent vegetative state, and death were found in $85.8 \%, 2 \%, 5.1 \%, 1.5 \%$, and $2.5 \%$ of the patients, respectively, according to Glasgow Outcome Scale.

Conclusion: Most of the patients were transferred to the hospital by ambulance. Pre-hospital fixation was required in more than half of the patients. Most of the patients showed GCS $\geq 13$ and a good recovery outcome, according to GCS.

* Corresponding Author:

Shahrokh Yousefzadeh-Chabok, MD.

Address: Guilan Road Trauma Research Center, Poursina Hospital, School of Medicine, Guilan University of Medical Sciences, Rasht, Iran Tel: +98 (13) 33311472

E-mail: neurosurgery97@yahoo.com 


\section{Highlights}

- EMS, non-surgical interventions, and GOS were evaluated in patients with traumatic spine.

- Most of the patients were transferred to the hospital by ambulance.

- Pre-hospital fixation was required in more than half of the patients.

- Most of the patients showed GCS $\geq 13$ and a good recovery outcome.

\section{Plain Language Summary}

We assessed the pre-hospital emergency services, non-surgical interventions, and clinical outcomes in patients with traumatic spine referred to Poursina hospital in Guilan during 2015 to 2019. 197 patients with traumatic spine were reviewed. $80.2 \%$ of the patients were transferred by ambulance. Pre-hospital fixation was performed in $59.4 \%$ of the patients $(n=117) .4 .6 \%$ of the patients had GCS $<9 ; 3 \%$ of them $(n=6)$ had $9<\mathrm{GCS}<12$; and $92.4 \%$ had GCS $\geq 13.11 .7 \%$ of the patients experienced spinal cord injury. $6.1 \%, 1 \%, 3 \%, 0.5 \%$, and $1 \%$ of the patients suffered from paraplegia, paraparesis, quadriplegia, quadriparesis and hemiparesis, respectively. Surgery was performed in $89.8 \%$ of the patients. Traction was performed for $3.6 \%$ of the patients. Good recovery, moderate disabilities, severe disabilities, persistent vegetative state, and death were found in $85.8 \%, 2 \%, 5.1 \%, 1.5 \%$, and $2.5 \%$ of the patients, respectively.

\section{Introduction}

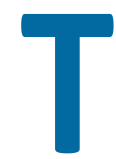

raumatic injuries are one of the main cause of disability and death all over the world [1]. Traumatic Spinal Cord Injury (SCI), commonly caused by automobile accidents, is a life-threatening situation by compromising the function of spinal cord [2]. Damage to any of the neural components of the spinal cord resulting in transient or constant sensory, motor, and autonomic deficits is considered as $\mathrm{SCl}$ [3]. Primary injury results from a mechanical force to the nervous tissue leading to direct damage and a secondary insult aggravating the condition [4]. Neuron and glial cell deaths arise from $\mathrm{SCl}$, or due to ischemia and infection [5]. SCl can cause complete and incomplete neurological deficits [6].

Approximately $2 \%$ of all patients with blunt trauma experience $\mathrm{SCl}$, and this ratio elevates to about $7.5 \%$ in multiple trauma patients [7, 8]. Multiple trauma patients are more prevalently suffer from $\mathrm{SCl}$, causing them structural and functional impairments. $\mathrm{SCl}$ also has a huge impact on patients' daily activity and their social involvements [9]. Inappropriate transportation of the $\mathrm{SCl}$ patients by Emergency Medical Service (EMS) officials before getting to medical centers should be taken seriously, as if not, it can deteriorate patients' condition. Proper pre-hospital immobilization of the spine and application of the "early hospital care" are two determinant factors reducing the possibility of sec- ondary neurological deficit. Medication and traction are two non-surgical management which can be used in patients with $\mathrm{SCl}$. Administration of methylprednisolone to traumatic $\mathrm{SCl}$ patients have always been a matter of controversy, but its routine administration to $\mathrm{SCl}$ patients is not recommended by the most recent guidelines [10-15]. However, the Second National Spinal Cord Injury Study strongly supports its helpful effect [16]. Traction is a procedure that applies to $\mathrm{SCl}$ patients to degrade existing pressure, in which a gap is formed between articular facets within the joint. As a result, the compression of the spinal neural root, and in turn, the risk of inflammation will be decreased [17].

Guilan is a province located in the north of Iran, and is surrounded by the Caspian Sea and Alborz mountain range. The geographical location of Guilan brought about gardens and farms and its nature absorbs tourists in various seasons. These features have caused Guilan to have a different trend in traumatic $\mathrm{SCl}$ compared with the other provinces of Iran. These also necessitate a well-managed EMS and hospital services. The aim of this study was to assess the pre-hospital EMS services, non-surgical interventions, and clinical outcomes in patients with traumatic $\mathrm{SCl}$ referred to Poursina hospital in Guilan. 


\section{Methods \& Materials/ Patients}

Present descriptive cross-sectional study was based on review of records of traumatic $\mathrm{SCl}$ patients admitted to the Poursina hospital trauma center in Rasht and registered to Guilan trauma center spinal cord injuries' registry during 2015 to 2019. Demographic data, as well as the data regarding the type of patients' transportation to hospitals, pre-hospital care given to the patients (fixation, intubation, CPR in cases with cardiac arrest, interhospital transportation, Glasgow Comma Scale (GCS) both prior and subsequent to hospital admission, type of the neurological deficit, existence and type of the $\mathrm{SCl}$, type of the non-surgical intervention, weight, duration and success rate of traction procedure, methylprednisolone administration, duration of stay of patients in Intensive Care Unit (ICU), and patients' outcome on discharge based on Glasgow Outcome Scale (GOS) were extracted from the registry system. The relative and absolute frequencies of each variable were assessed using the SPSS V. 22. A secondary analysis of the association between pre-hospital measures and the non-surgical interventions with patients' outcome was also carried out using discriminant analysis.

\section{Result}

Overall, records of 197 patients with traumatic SCl in Poursina Hospital trauma center registry were reviewed. The Mean \pm SD age of patients was $40.05 \pm 16.3$ years. Based on this survey, 197 patients (75.6\%) were male, 48 patients were female ( $24.4 \%$ ), and male/ female ratio was 3.1:1. Out of 197 participants, 158 (80.2\%) of them were transferred by ambulance, and among them, 83 (42.1\%) had inter-hospital transmission. Pre-hospital fixation was performed for $59.4 \%$ of the patients ( $n=117)$. Pre-hospital fixation of the neck, spine, and limbs were performed for $41.6 \%(n=82), 42.6 \%(n=84)$, and $26.9 \%$ $(n=53)$ of the patients, respectively.

Pre-hospital intubation was performed for only $1 \%$ of patients $(n=2)$. Nine patients (4.6\%) had GCS $<9,3 \%$ of them $(n=6)$ had $9<$ GCS $<12$, and $92.4 \%$ had GCS $\geq 13$ $(n=182)$. Twenty-three $(11.7 \%)$ patients $(n=23)$ had spinal cord injuries and $88.3 \%(n=174)$ showed no evidence of $\mathrm{SCl}$. The type of spinal cord injuries included $6.1 \%(n=12)$ paraplegia, $1 \%(n=2)$ paraparesis, $3 \%(n=6)$ quadriplegia, $0.5 \%(n=1)$ quadriparesis, $1 \%(n=2)$ hemiparesis, and $88.3 \%(n=174)$ had no sign of $\mathrm{SCl}$.

Surgery was performed for $89.8 \%$ of the patients ( $n=$ $177)$, while $10.2 \%(n=20)$ did not receive any kind of surgical interventions. Traction procedure was performed for only $3.6 \%$ of the patients ( $n=7)$, and $28.6 \%$ of them $(n=2)$ were successful. Duration of traction applied to these seven patients were $36,41,45,72,96,111$, and 275 hours. Weight of traction for $14.3 \%$ of patients $(n=1)$ was $2 \mathrm{~kg}$, for $28.6 \%$ of patients $(n=2)$ was $4 \mathrm{~kg}$, for $14.3 \%(n=1)$ was $5 \mathrm{~kg}$, for $28.6 \%$ was $(n=2) 7 \mathrm{~kg}$, for $14.3 \%$ was $(n=1) 13 \mathrm{~kg}$.

Approximately one fifth (20.8\%) of the patients were kept in ICU. Eventually, data showed that 3\% of the patients discharged by personal consent, $85.8 \%$ went home with good recovery, $2 \%$ discharged with moderate disabilities, 5.1\% discharged with severe disabilities, and $1.5 \%$ were discharged with persistent vegetative state. Unfortunately, $2.5 \%$ of the patients died.

\section{Discussion}

The aim of this study was to assess the pre-hospital EMS services, non-surgical interventions, and clinical outcomes in patients with traumatic $\mathrm{SCl}$ referred to Poursina hospital in Guilan. Our results indicated that the mean age of patients was 40.05 with a standard deviation of 16.30. In Miekisiak's study, out of 108 patients, 70 were 45 years or younger and 38 were more than 45 years old [18]. In a study conducted by Kreinest and colleagues, the Mean $\pm S D$ age of patients was $50.5 \pm 21.2$ [19]. In Ahidjo's study, the mean age of patients was 36.4 \pm 12.7 [20]. In Chikuda's study, the mean age of patients was $60.8 \pm 18.7$ [21]. In Eo Uche's study, the Mean $\pm S D$ age of patients was $40.4 \pm 1.1$ [22].

In our study, the male/ female ratio was 3.1:1. In Ahidjo's study, M/F ratio was 7.8:1 [20]. In Kreinest's study, M/ F was 3.58:1 [19]. In Oteir's study, the male to female ratio varied from 1.6:1 in an Irish study to 6:1 in a study in New South Wales Australia [23]. In Chikuda's study, M/ F was 3:1 [21]. In Eo Uche's study, M/ F was 4.8:1 [22].

In our study, $59.4 \%$ of the patients were immobilized in the pre-hospital setting, $41.6 \%$ underwent cervical spine immobilization prior to hospital admission, spine immobilization was performed for $42.6 \%$ of them, and $26.9 \%$ had their limb immobilized before entering the hospital. In Kreinest's study, in the pre-hospital phase, $69.9 \%$ of the patients with traumatic $\mathrm{SCl}$ were immobilized on boards or vacuum mattresses. The cervical spine was immobilized for $81.0 \%$ of the patients using cervical collars. Out of 60 patients suffering from traumatic cervical SCl, 47 (78.3\%) received neck collars. 
Complete immobilization was performed in nearly half (56.7\%) of the patients, and $20 \%$ of patients were not immobilized in any way. Only one patient who was not immobilized suffered from severe associated injuries and hemodynamic instability caused by hemorrhagic shock [19]. In McDonald's study, 66 of 1129 patients (6.73\%) were immobilized in the pre-hospital settings. Regarding the reasons for non-immobilization, the injuries of 30 patients were not identified by protocol assessment (false negative), and 26 patients were not immobilized despite a positive protocol assessment (true positive) [24].

In a systematic review conducted by Henry Ahn's, up to $8 \%$ of spinal injuries were not immobilized and both emergency physician and EMS providers indicated immobilization in $60 \%$ of patients. In another systematic review by Domeier et al., the sensitivity of EMS protocol for spine immobilization in $\mathrm{SCls}$ was $92 \%$, and $8 \%$ of patients did not have immobilization. However, none of the non-immobilized patients have sustained spinal cord injuries. EMS providers immobilized $12 \%$ of patients with no indication according to the protocol [25]. In Terje Sundstrom's study, 3-25\% of spinal cord injuries are secondary, occurring either during pre-hospital or early hospital care and are the result of inappropriate management, such as lack of spinal immobilization [26]. According to Oteir's review study, about $40 \%$ of trauma patients could be transported without c-spine immobilization [23].

In our study, $80.2 \%$ of the patients were transported by ambulance. In Henry Ahn's systematic review study, $41 \%$ of transportation of patients with $\mathrm{SCl}$ (complete or incomplete) was achieved by ground ambulance, 54\% by helicopter, $5 \%$ by fixed-wing aircraft. Among them, $84 \%$ were transferred within $24 \mathrm{~h}$ of injury. No patient suffered ascending injury level as a result of transfer. In this study, there was no significant difference in the probability of improvement between ground and air transportation.

In the recent systematic review study conducted by Flabouis et al., the majority of transfers (93\%) were by helicopter, followed by fixed-wing aircraft (3.5\%), and lastly road vehicles [25]. In Kreinest's study, $58.6 \%$ of patients were transferred by air (helicopter) to a first level trauma center [19]. In Ahidjo's study, 54.2\% of patients were transferred by solon car, $24.4 \%$ by commercial bus, $13.7 \%$ by open truck, $5.4 \%$ by ambulance, and $2.4 \%$ by motorcycle [20].
In our study, $6.1 \%$ of the patients $(n=12)$ experienced paraplegia, $1 \%$ of the patients $(n=2)$ showed paraparesis, $3 \%$ of the patients had $(n=6)$ quadriplegia, $0.5 \%$ of the patients $(n=1)$ experienced quadriparesis, $1 \%$ of the patients $(n=2)$ had hemiparesis, and $88.3 \%$ of the patients ( $n=174$ ) of the patients did not have any types of $\mathrm{SCl}$. In McDonald's study, of 72 patients, 71 had no neurological deficit except for one patient who discharged with residual quadriparesis [24].

Our results showed that only $1 \%$ of the patients were intubated in the pre-hospital phase. Henry Ahn' systematic review revealed that most studies examining airway management were performed in the hospital rather than in the pre-hospital setting, and also that studies did not assess intubation done by emergency medical technician in the field and there was only one article examining pre-hospital intubation and factors influencing successful intubation in the pre-hospital setting. This prospective study evaluated 4691 transported patients, of which 236 required intubation [25].

In our study, $42.1 \%$ of patients had inter-hospital transfers. In Ahidjo's study, $25 \%$ of patients were transferred directly to the hospital accident center and $75 \%$ of patients had several previous hospital visits [20].

Our results showed that only $10.2 \%$ of patients received non-surgical treatments. Miekisiak et al. showed that nearly three quarters $(73.1 \%)$ of all the respondents declared the use of steroids for acute $\mathrm{SCl}$ [18]. In Kreinest's study, methylprednisolone was administered in the pre-hospital phase in $32.8 \%$ of patients [19]. In Schroeder's study, $46 \%$ of surgeons used steroids for complete cervical spinal cord injury and $56 \%$ of surgeons used steroids for incomplete cervical spinal cord injury as well.

Also, $46 \%$ and $55 \%$ of surgeons used steroids for complete and incomplete thoracolumbar spinal cord injuries, respectively [27]. In Sunshine's study, $51.4 \%$ of patients received methylprednisolone during the acute phase of injury. In this study, $78 \%$ of patients underwent surgical intervention ( $22 \%$ non-surgical intervention) [28]. In Chikuda's study, 23.4\% of patients received more than or equal to $5000 \mathrm{mg}$ (high dose) methylprednisolone [21]. Elsewhere, $2.95 \%$ of patients received methylprednisolone [29].

Here in this study, only $3.6 \%$ of patients $(n=7)$ had traction and the success rate was $28.6 \%(n=2)$. Duration of traction for the 7 patients was 36, 41, 45, 72, 96, 111, and 275 hours. Weight of traction for $14.3 \%$ of patients 
( $n=1)$ was $2 \mathrm{~kg}$, for $28.6 \%$ of patients ( $n=2)$ was $4 \mathrm{~kg}$, for $14.3 \%$ ( $n=1$ ) was $5 \mathrm{~kg}$, for $28.6 \%$ was $(n=2) 7 \mathrm{~kg}$, for $14.3 \%$ was $(n=1) 13 \mathrm{~kg}$.

In Eo Uche's study, 127 patients with cervical spinal injured were treated with skull traction. However, only 105 patients had complete records and were studied. Traction weight was calculated using $2.3 \mathrm{~kg}$ per level of injury and was performed with incremental $5 \mathrm{~kg}$ weights under $\mathrm{X}$-ray control till reduction was achieved. To maintain the reduction, they applied $2.5 \mathrm{~kg}$ plus $1 \mathrm{~kg}$ per level of cervical injury [22]. One of the limitations of our study was patients' incomplete records, which made us to excluded their data. Another limitation was various evaluators that may cause differences in recorded results.

\section{Conclusion}

Pre-hospital management of patients with possible $\mathrm{SCl}$ minimizes secondary $\mathrm{SCl}$ and potential morbidity related to the lack of immobilization.

\section{Ethical Considerations}

Compliance with ethical guidelines

This study was performed in accordance with the guidelines of the research ethics committee of Guilan University of Medical Sciences (Approval Code: IR.GUMS.REC.1397.520).

Funding

This research did nor receive any specific grant from funding agencies in the public, commercial, or not-forprofit sectors.

\section{Authors contributions}

All authors met the ICMJE criteria. Sasan Andalib and Zahra Mohtasham-Amiri (co-first authors) contributed equally to this paper.

\section{Conflict of interest}

Authors declare no conflict of interest for this paper.

\section{Acknowledgements}

We would like to thank Guilan Road Trauma Research Center for its support.

\section{References}

[1] Pirouzmand F. Epidemiological trends of spine and spinal cord injuries in the largest Canadian adult trauma center from 1986 to 2006. Journal of Neurosurgery Spine. 2010; 12(2):13140. [DOI:10.3171/2009.9.SPINE0943] [PMID]

[2] Andalib S, Mohtasham-Amiri Z, Yousefzadeh-Chabok Sh Saberi A, Emamhadi MR, Kouchakinejad-Eramsadati L, et al. Traumatic spinal cord injuries due to motor vehicle accidents. Iranian Journal of Neurosurgery. 2018; 4(4):213-8. [DOI:10.32598/irjns.4.4.195]

[3] O'Connor P. Incidence and patterns of spinal cord injury in Australia. Accident; Analysis and Prevention. 2002; 34(4):40515. [DOI:10.1016/S0001-4575(01)00036-7]

[4] Emamhadi MR, Soltani B, Yousefzadeh-Chabok Sh, Babaee $\mathrm{P}$, Behzadnia H, Ghadarjani Sh, et al. Evaluation of mesenchymal stem cells and granulocyte colony stimulating factor in treatment of complete spinal cord injury. Journal of Experimental \& Clinical NeuroSciences. 2018; 5(1):1-5.

[5] Andalib S, Mohtasham-Amiri Z, Yousefzadeh-Chabok Sh Saberi A, Reihanian Z, Kouchakinejad-Eramsadat L, et al Epidemiology of spine trauma and spinal cord injuries in the north of Iran. Iranian Journal of Neurosurgery. 2018; 4(4):199204. [DOI:10.32598/irjns.4.4.180]

[6] Andalib S, Mohtasham-Amiri Z, Yousefzadeh-Chabok Sh Saberi A, Behzadnia H, Kouchakinejad-Eramsadat L, et al. Assessment of surgery, complications, and clinical outcomes in patients with traumatic spine. Iranian Journal of Neurosurgery. 2019; 5(1):1.

[7] Crosby ET. Airway management in adults after cervical spine trauma. Anesthesiology. 2006; 104(6):1293-318, [DOI:10.1097/00000542-200606000-00026] [PMID]

[8] Stephan K, Huber S, Häberle S, Kanz KG, Bühren V, van Griensven $\mathrm{M}$, et al. Spinal cord injury--incidence, prognosis, and outcome: An analysis of the TraumaRegister DGU. The Spine Journal. 2015; 15(9):1994-2001. [DOI:10.1016/j. spinee.2015.04.041] [PMID]

[9] Kirchberger I, Biering-Sorensen F, Charlifue S, Baumberger M, Campbell R, Kovindha A, et al. Identification of the most common problems in functioning of individuals with spinal cord injury using the International Classification of Functioning, Disability and Health. Spinal Cord. 2010; 48(3):221-9. [DOI:10.1038/sc.2009.116] [PMID]

[10] Evaniew N, Dvorak M. Cochrane in CORR $($ : Steroids for acute spinal cord injury (review). Clinical Orthopaedics and Related Research ${ }^{\circledR}$. 2016; 474(1):19-24. [DOI:10.1007/s11999015-4601-6] [PMID] [PMCID]

[11] Breslin K, Agrawal D. The use of methylprednisolone in acute spinal cord injury: A review of the evidence, controversies, and recommendations. Pediatric Emergency Care. 2012; 28(11):1238-45. [DOI:10.1097/PEC.0b013e3182724434] [PMID]

[12] Hurlbert RJ. Methylprednisolone for the treatment of acute spinal cord injury: Point. Neurosurgery. 2014; 61(Suppl. 1):325. [DOI:10.1227/NEU.0000000000000393] [PMID]

[13] Fehlings MG, Wilson JR, Cho N. Methylprednisolone for the treatment of acute spinal cord injury: Counterpoint. Neurosurgery. 2014; 61(Suppl. 1):36-42. [DOI:10.1227/ NEU.0000000000000412] [PMID] 
[14] Witiw CD, Fehlings MG. Acute spinal cord injury. Journal of Spinal Disorders \& Techniques. 2015; 28(6):202-10. [DOI:10.1097/BSD.0000000000000287] [PMID]

[15] Hurlbert RJ, Hadley MN, Walters BC, Aarabi B, Dhall SS, Gelb DE, et al. Pharmacological therapy for acute spinal cord injury. Neurosurgery. 2013; 72(Suppl. 2):93-105. [DOI:10.1227/NEU.0b013e31827765c6] [PMID]

[16] Bracken MB, Shepard MJ, Collins WF, Holford TR, Young W, Baskin DS, et al. A randomized, controlled trial of methylprednisolone or naloxone in the treatment of acute spinalcord injury -- results of the second national acute spinal cord injury study. The New England Journal of Medicine. 1990; 322(20):1405-11. [DOI:10.1056/NEJM199005173222001] [PMID]

[17] Farajpour H, Jamshidi N. Effects of different angles of the traction table on lumbar spine ligaments: A finite element study. Clinics in Orthopedic Surgery. 2017; 9(4):480-8 [DOI:10.4055/cios.2017.9.4.480] [PMID] [PMCID]

[18] Miekisiak G, Kloc W, Janusz W, Kaczmarczyk J, Latka D, Zarzycki D. Current use of methylprednisolone for acute spinal cord injury in Poland: Survey study. European Journal of Orthopaedic Surgery \& Traumatology. 2014; 24(Suppl. 1):26973. [DOI:10.1007/s00590-014-1422-3] [PMID]

[19] Kreinest M, Ludes L, Turk A, Grutzner PA, Biglari B, MatschkeS. Analysis of prehospital care and emergency room treatment of patients with acute traumatic spinal cord injury: A retrospective cohort study on the implementation of current guidelines. Spinal Cord. 2017; 55(1):16-9. [DOI:10.1038/ sc.2016.84] [PMID]

[20] Ahidjo KA, Olayinka SA, Ayokunle O, Mustapha AF, Sulaiman GAA, Gbolahan AT. Prehospital transport of patients with spinal cord injury in Nigeria. The Journal of Spinal Cord Medicine. 2011; 34(3):308-11. [DOI:10.1179/10790261 0X12883422813624] [PMID] [PMCID]

[21] Chikuda H, Yasunaga H, Takeshita K, Horiguchi H, Kawaguchi $\mathrm{H}$, Ohe K, et al. Mortality and morbidity after high-dose methylprednisolone treatment in patients with acute cervical spinal cord injury: A propensity-matched analysis using a nationwide administrative database. Emergency Medicine Journal. 2014; 31(3):201-6. [DOI:10.1136/emermed-2012-202058] [PMID] [PMCID]

[22] Uche EO, Nwankwo OE, Okorie E, Muobike A. Skull traction for cervical spinal injury in Enugu: A 5-year retrospective multicenter analysis of the clinical outcomes of patients treated with two common devices. Nigerian Journal of Clinical Practice. 2016; 19(5):580-4. [DOI:10.4103/1119-3077.188713] [PMID]

[23] Oteir AO, Smith K, Jennings PA, Stoelwinder JU. The prehospital management of suspected spinal cord injury: An update. Prehospital and Disaster Medicine. 2014; 29(4):399-402. [DOI:10.1017/S1049023X14000752] [PMID]

[24] McDonald NE, Curran-Sills G, Thomas RE. Outcomes and characteristics of non-immobilised, spine-injured trauma patients: A systematic review of prehospital selective immobilisation protocols. Emergency Medicine Journal. 2016; 33(10):732-40. [DOI:10.1136/emermed-2015-204693] [PMID]

[25] Ahn H, Singh J, Nathens A, MacDonald RD, Travers A, Tallon J, et al. Pre-hospital care management of a potential spinal cord injured patient: A systematic review of the literature and evidence-based guidelines. Journal of Neurotrauma. 2011 28(8):1341-61. [DOI:10.1089/neu.2009.1168] [PMID] [PMCID]

[26] Sundstrom T, Asbjornsen H, Habiba S, Sunde GA, Wester K. Prehospital use of cervical collars in trauma patients: A critical review. Journal of Neurotrauma. 2014; 31(6):531-40. [DOI:10.1089/neu.2013.3094] [PMID] [PMCID]

[27] Schroeder GD, Kwon BK, Eck JC, Savage JW, Hsu WK, Patel AA. Survey of cervical spine research society members on the use of high-dose steroids for acute spinal cord injuries. Spine. 2014; 39(12):971-7. [DOI:10.1097/BRS.0000000000000297] [PMID]

[28] Sunshine JE, Dagal A, Burns SP, Bransford RJ, Zhang F, Newman SF, et al. Methylprednisolone therapy in acute traumatic spinal cord injury: Analysis of a regional spinal cord model systems database. Anesthesia and Analgesia. 2017 124(4):1200-5. [DOI:10.1213/ANE.0000000000001906] [PMID]

[29] Evaniew N, Noonan VK, Fallah N, Kwon BK, Rivers CS, Ahn $\mathrm{H}$, et al. Methylprednisolone for the treatment of patients with acute spinal cord injuries: A propensity score-matched cohort study from a canadian multi-center spinal cord injury registry. Journal of Neurotrauma. 2015; 32(21):1674-83. [DOI:10.1089/neu.2015.3963] [PMID] [PMCID] 